\title{
Physiotherapy in Dementia
}

\author{
Urmi Chavan* \\ MSc Advancing Physiotherapy Practice, UK \\ *Corresponding author: Urmi Chavan, MSc Advancing Physiotherapy Practice, UK
}

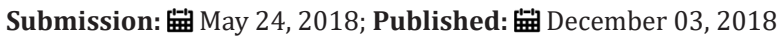

\section{Introduction}

We live in a maturing world, and that is closely associated with conditions, such as, osteoarthritis, osteoporosis, cataracts, stroke, growth, coronary supply route illness and dementia, which increasingly affect the group wellbeing Guccione 2011. Of these conditions, dementia emerges as the one to inspire dread in those contemplating over a solid seniority. The likelihood of turning

out to be rationally clumsy, absent minded, and dependant can be extremely aggravating [1]. Consequently, it is critical to concentrate on and comprehend the condition keeping in mind the end goal is to guarantee ideal patient consideration while treating patients with dementia auxiliary to a basic management as a physiotherapist (Table 1).

Table 1: Risk factors contributing to the development of the disease are as follows.

\begin{tabular}{|c|c|}
\hline Genetic & $\begin{array}{c}\text { Certain types of early-onset, autosomal dominant AD are associated with gene mutations on chromosome } 21 \text {, chromosome } \\
14 \text {, and chromosome } 1 \text { and account for approximately } 2 \% \text { of the population presenting with AD. However, the presence of } \\
\text { the APOE } € 4 \text { allele on chromosome } 19 \text { has been associated with a considerably greater risk for developing the more common, } \\
\text { late-onset form of AD. It must be remembered that possessing the } \epsilon 4 \text { allele is neither necessary nor sufficient for the develop- } \\
\text { ment of AD [31]. }\end{array}$ \\
\hline $\begin{array}{c}\text { Amyloid Plaques } \\
\text { in } \mathrm{AD}\end{array}$ & $\begin{array}{l}\text { The senile plaques consist of largely soluble deposits of proteins called as beta-amyloid proteins, and therefore sometimes } \\
\text { called as amyloid plaques. This protein is derived from a larger protein called amyloid precursor protein (APP). The beta amy- } \\
\text { loid aggregates and mixes with debris from the nerve cells and other cells to form the plaques. These are predominantly found } \\
\text { in areas of brain used for memory and other cognitive functions - the hippocampus, medial temporal lobe and parietal lobe. } \\
\text { Amyloid production is central to the disease process [51]. }\end{array}$ \\
\hline Neurodegeneration & $\begin{array}{c}\text { Alzheimer's disease is characterized by abnormal cell death of vulnerable nerve cells in region of the brain that are essential to } \\
\text { normal cognitive function. It is this cell death that results in atrophy, detectable on brain scans. The soluble beta amyloid oligo- } \\
\text { mers cause more cell damage than insoluble plaques. Beta -amyloid may increase cell apoptosis in brain, an essentially normal } \\
\text { process that helps remove unnecessary or diseased cells, but which in adult brain may result in irreversible loss of brain cells } \\
\text { and function [63]. }\end{array}$ \\
\hline $\begin{array}{c}\text { Neurofibrillary } \\
\text { tangles (NFT) and tau } \\
\text { proteins }\end{array}$ & $\begin{array}{c}\text { Tau proteins stabilize the microtubules in the neurons that are essential for the fast transport of microscopic components } \\
\text { through the nerve cell. Damage to the microtubules disrupts the internal transport network of neurons resulting in the im- } \\
\text { paired communication between neurons. In Alzheimer's disease, tau protein loses its ability to promote microtubule assembly } \\
\text { and forms into NFT [48]. }\end{array}$ \\
\hline
\end{tabular}

"Dementia" is principally a term used to portray a gathering of manifestations that might be brought on by various distinctive ailments. This incorporates Alzheimer's infection, vascular dementia, frontal temporal dementia and dementia with Lewy bodies Curran 2004. The dementia syndrome is primarily defined as an "acquired decline in memory and cognition due to brain disease that results in significant impairment of personal, social, or occupational function". Other mind works that are influenced incorporate orientation, calculation, comprehension, computation, perception, learning limit, dialect, judgment, reasoning and information processing Agronin 2004.

Dementia typically presents in the following 5 stages:

A. Pre-dementia, questionable or mild cognitive dementia

B. Mild or early dementia

\section{Moderate or middle stage dementia \\ D. Severe or late stage dementia \\ E. Advanced-dementia}

\section{Types of Dementia}

There are over a 100 sorts of dementia which have been established, be that as it may, the greater part of these sorts is uncommon. The four fundamental sorts of dementia seen in clinical practice are as per the following:
A. Alzheimer's disease
B. Vascular dementia
C. Dementia with Lewy bodies. 
Table 2: [1], described dementia to be progressing in the following stages.

\begin{tabular}{|c|c|}
\hline Stage & Clinical Features \\
\hline \multirow{6}{*}{$\begin{array}{l}\text { Pre-Dementia, Questionable Dementia or } \\
\text { Mild Cognitive Impairment }\end{array}$} & $\begin{array}{c}\text { There is no set pattern and the various symptoms often occur independently of each other and are often } \\
\text { only recognised retrospectively }\end{array}$ \\
\hline & Subjective awareness of short term memory deficits and or close friends/ relatives notice mild change \\
\hline & Depression and anxiety along with other non-specific behaviour or memory changes. \\
\hline & Personality changes such as apathy and irritability often attributed to age or depression. \\
\hline & Close relationships might become strained, fewer social and hobby activities. \\
\hline & Work performance, decision making and problem solving difficulties may occur \\
\hline \multirow{8}{*}{ Mild or Early Dementia } & $\begin{array}{l}\text { Consistent deficits across a range of domains, however usually still able to function with minimum assis- } \\
\text { tance: }\end{array}$ \\
\hline & $\begin{array}{c}\text { Impairment in short term memory interferes with day to day function. e.g.- losing keys, forgetting conver- } \\
\text { sations. }\end{array}$ \\
\hline & Some disorientation in time, e.g.- date and may become disorientated when in unfamiliar places. \\
\hline & Some word-finding difficulties - names, objects \\
\hline & Obvious difficulties with problem solving, especially in novel situations \\
\hline & $\begin{array}{l}\text { Difficulties in social functioning, for example, shopping, finances or business affairs, though may superfi- } \\
\text { cially appear normal and engage in them. }\end{array}$ \\
\hline & More difficult household tasks no longer done and less interest in hobbies. \\
\hline & May require prompting in personal care. \\
\hline \multirow{10}{*}{ Moderate or Middle Stage Dementia } & $\begin{array}{c}\text { More severe deficits, clearly needs assistance from a caregiver to function at a level comparable to before } \\
\text { onset of dementia }\end{array}$ \\
\hline & Severe memory loss and rapidly forgets new information \\
\hline & Usually disorientated in time and often place \\
\hline & Obvious difficulties in finding words, often doesn't speak spontaneously \\
\hline & Starts to misidentify familiar people \\
\hline & Problem solving and judgement very poor \\
\hline & Unable to function independently in social situations, but is usually able to attend with supervision \\
\hline & Only able to perform simple chores at home \\
\hline & Requires assistance with personal care \\
\hline & Behavioural difficulties emerge, e.g. wandering, agitation, aggression, psychosis, sleep disturbance. \\
\hline \multirow{10}{*}{ Severe or Late Stage Dementia } & No semblance of independent function, therefore majority of persons are in residential care. \\
\hline & Very severe memory loss, only fragments remain \\
\hline & Oriented to person ( they know who they are, but not the place or time) \\
\hline & Unable to solve problems or make judgements \\
\hline & Language skills limited to a few words and phrases \\
\hline & Regularly misidentifies familiar people \\
\hline & Social function is minimal even with supervision \\
\hline & No significant self-care capacity \\
\hline & Frequent incontinence \\
\hline & Behavioural difficulties increase. \\
\hline
\end{tabular}




\begin{tabular}{|l|c|}
\hline \multirow{4}{*}{ Advanced Dementia } & Completely dependent on care-givers for all aspects of activities of daily living. \\
\cline { 2 - 3 } & No semblance of memory function \\
\cline { 2 - 3 } & Usually inarticulate, maybe mute. \\
\cline { 2 - 3 } & Cannot identify familiar people. \\
\cline { 2 - 3 } & Very poor comprehension of verbal commands \\
\cline { 2 - 3 } & Social interactions virtually non-existent \\
\hline & May lose capacity to stand, walk, sit up \\
\hline
\end{tabular}

Further information to support this can be found in Appendix (Table 2).

\section{Prevalence of Dementia}

Prevalence is the number of people with dementia at a given point in time Barker 1990. The worldwide predominance of dementia is prone to be as high as 24 million and is anticipated to double at regular intervals through to 2040, resulting to a costly burden of disease [2]. As indicated by the World Alzheimer's report released in 2015, approximately 46.8 million individuals worldwide are living with dementia in 2015. This number will double rapidly to 74.7 million in 2030 and 131.5 million in 2050 These new estimates are $12-13 \%$ higher than those made for the World Alzheimer Report 2009. Europe is currently said to have 10.46 million citizens diagnosed with dementia, and this number is said to increase proportionately by $28 \%$ by the year 2030 , whereas, South East Asia is currently having an estimated 3.6 million people with dementia with a proportionate rise by $82 \%$ by the year 2030 .

\section{Social Influences of Dementia}

Unfortunately, dementia is a medical condition along with being a social taboo. Dementia has a profound impact on the patient, as well as on the lives of everyone closely related to the individual; Spouses, partners, family, friends. Dementia is diagnosis presenting with various behavioural and psychological symptoms as previously explained, as a result of which there is a serious social and health impacts for the patient as well as family carers. Hence, it is important to shed light on the social environment that the patient receives physiotherapy care in, how they differ and how the consequences vary in relation to the environment. There is evidence suggesting that the persons with dementia living alone or being institutionalized differ from those living with others in their demographic characteristics and service utilization patterns [3]. This includes increased risk of depression, severity of dementia, integrity of social network, degree of disability and mood disturbances associated with institutionalization Hebert 2000.

Decision making is an important aspect of dementia centred care. When a patient is unable to make decisions for themselves, the staff must do what is in best interest of the patient [4]. This would mainly focus on collaborative practice in terms of involving the patient as much as possible in the decision-making process, taking into consideration their views and wishes, even if they are incapable of making an actual decision [5]. It would typically incorporate their cultural beliefs, collaboration with family and friends, to get a better insight into individual's interests, personal background, and personality before being diagnosed with dementia [6]. Hence, helping the therapist understand the activities that they patient would have consented for, and incorporate them in the treatment protocol [7]. The same can be applied by physiotherapists when dealing with patients with post stroke, mental incapacities etc.

\section{Political Influences of Dementia}

Understanding the burden of dementia is pivotal in establishing care and services for individuals with dementia. This report aims to focus and discuss the economic impact of dementia on two countries in particular, i.e. India and United Kingdom.

\section{Impact in india}

Understanding the burden of dementia is vital for developing and promoting dementia care and management in the Low and Middle Income Countries. According to the dementia India report published in 2010, there were 3.7 million Indians with dementia with the total societal costs were approximately 14,700 crores. While the stated numbers are expected to double by 2030 , expenses would expand three times. The report likewise examined the Global Burden of Disease report which demonstrated that long standing non-transmittable diseases are quickly turning into principal causes for sickness in all developing countries with the exception of Sub-Saharan Africa Fuster and Voute 2005.

In developing regions, the legitimacy and integrity of the family care system is frequently overestimated. There are no precise approximations for the treatment gap for dementia in India, however it is estimated that this breach surpasses $90 \%$ in many parts of the nation. The major barriers to closing the gap include lack of awareness about dementia and lack of human resources for the care of people with dementia. India needs financial and human funding to accomplish broad scope of specialized expertise, Prince 2007. Therefore, the challenge for India is to formulate culturally relevant management strategies that can be delivered with available resources, such as educating and counselling families on their role as care providers. The model of care in developing countries should be based on home care, along with providing guidance for family [8].

\section{In united kingdom}

The health and social services and revenue losses due to dementia for the year 2008 for UK were estimated to be $£ 23.0$ billion. Prolonged initialization and overall care expenditures 
constituted nearly $95 \%$ of these costs. While, wellbeing and social care expenses were evaluated at $£ 10.3$ billion, the yearly cost per instance of dementia was assessed to be $£ 27,647$, which was substantially more than the average income in UK $(£ 24,700)$. In the event that present patterns proceed, and no move is made, the quantity of individuals with dementia in the UK is figuring to increment to $1,142,677$ by 2025 and 2,092,945 by 2051, an expansion of $40 \%$ throughout the following 12 years and of $156 \%$ over the course of the next 38 years. The state aims to combat this by enhancing prevention, support during and after prognosis, greater personal control, end of life care and encouraging research in the field of dementia (Department of Health report).

Physiotherapy administrations for individuals with dementia have been distinguished as key in adding to a cost sparing of $€ 6$ million a year. The chartered society of physiotherapy, UK, in line with the NICE guidelines advices physiotherapists to prescribe exercises to reduce dependence by maintaining/increasing mobility of patients, end of life care by managing painful contractures, patient positioning and management of painful contractures [9]. Physiotherapy, specifically exercises, to be a clinically effective and economical intervention. It promotes and advances movement for individuals with dementia [9]. Physiotherapy intercessions enhance the personal satisfaction for those with dementia and lessen the burden of care [10].

\section{Scope of Physiotherapy in Dementia}

Physiotherapists have historically been involved in treatment of various conditions including neurological, orthopaedic, musculoskeletal, and cardio-respiratory and the field of gerontology. The Chartered Society of Physiotherapy, 2002, identified the fundamental role of physiotherapy to be 'concerned with human function and movement and maximising potential'. In contrast, when the primitive pioneers identified the need to provide special care and services for people suffering from dementia, it was mainly concerned with providing conditions suitable for prolonged hospital stay. This included a dormitory, limited toilet and bathing facilities and inadequate staffing Whitehead 1978. Warren in 1960, however, shed light on the significance of active rehabilitation and how it could change the final years of patients who were put aside, and made to anticipate demise.

The majority of patients assessed and treated by physiotherapists are elderly. The conditions and symptoms that a physiotherapist may have to deal with can therefore be divided into 2 groups:

A. Physical problems commonly experienced by elderly.

B. Elderly presenting with symptoms specific to dementia

As a physiotherapist targets a variety of structural as well as psychological deficits in demented patients and provides treatment for the same, the significance of interaction plays a vital role in building up a therapeutic relationship, leading to successful assessment and treatment Orange 1998. The key, therefore, as a physiotherapist is to adapt communication strategies unique to patients with dementia in clinical practice. These may include:
A. Use of short simple words and sentences as longer sentences may be overwhelming Murphy 2012.

B. Being aware of speed and clarity. Use a gentle and relaxed tone - a lower pitch is more calming.

C. Repeat information or questions as needed Murphy 2012.

D. Use of Positive phrases. Instead of saying, "Don't go there," say, "Let's go here."

E. Give clues. To create a better understanding of the task required of the patient, point out to or touch the object to initiate the task.

F. Use of senses - (auditory, visual, tactile) Information that is easy to encode [11].

G. Convey a compliant manner. Know about your emotions and state of mind- you might convey through your manner of speaking. Use positive, amicable outward appearances and nonverbal correspondence [12].

The importance of body language including greeting, eye contact, bodily expressions of caring and attentiveness, body position and orientation has a tremendous positive impact on the outcome [13]. All conduct in an interactional circumstance has a message value and is in this manner communication [14]. Accordingly, experience and reflecting on communication techniques are key aspects to developing a therapeutic relationship and alliance formation. The assessment of a dementia patient by a physiotherapist would essentially aim to identify the impact of dementia on the patient's way of moving and breathing, postural control, balance abnormalities, the muscle tension and strength deficits. A physiotherapist should also ideally obtain collateral information from the relatives or carers pertaining to the patient's previous interests and personality and be able to integrate that information in order to modify techniques of assessment and treatment to suit the demented individual [15]. This would further 5 contribute to a broader view of the patients, ensuring the use of bio psychosocial model in adapting a holistic approach, which is particularly necessary in patients with dementia Taft 1997.

Following a thorough assessment, the physiotherapy treatment must be based on individual ability, capacity and interest. It may primarily include mobility exercises, as patients with dementia should be given favourable circumstances for goal targeted movements/ activities in a simple and precise way to maintain mobility and transfer skills and reduce decline in ADLs Oddy 1998. Simple techniques such as Body awareness therapy which acknowledges the influence of body and mind on each other with the use of fundamental, easy to understand movements, making it particularly valuable for patients with dementia Gyllensten 2003. Techniques such as massage, which stimulates the physical and psychological processes, may also be used to reduce muscle tension, pain sensitivity and anxiety Uvnas-Moberg 2004. In conclusion, physiotherapist plays a vital role in rehabilitation of patients with dementia with respect to maintenance of function and mobility. Physiotherapists, as autonomous practitioners, can embrace the nitty gritty, 
custom-made evaluations of the hindrances, movement confinements and participatory constraints confronted by individuals with dementia. Physiotherapists can work as a part of multidisciplinary team in order to provide high quality care to individuals suffering from dementia by promoting and maintaining independence according to NICE guidelines for physiotherapists.

\section{Evidence based physiotherapy practice}

Physiotherapists use movement governed therapy to achieve physical, mental and social prosperity [16]. Physiotherapists are commonly involved in rehabilitation of the numerous symptoms presented by dementia including reduced mobility, balance affection, pain and play an important role in retaining movement and function in people with dementia, in turn improving their quality of life Chartered Society of Physiotherapy 2002.

When treating a dementia patient, the assessment of the level of cognitive impairment is extremely significant. This would indicate the level of mental incapacity and degree of memory loss, which would be highly influential in the assessment and treatment protocol formulated by the physiotherapist. The most commonly used screening test used by physiotherapists is the Mini Mental State Examination (MMSE). However, evidence suggests low sensitivity and specificity of the test [17], and is also influenced by the level of literacy, thereby lowering the degree of universality of the scale. Hence, the use of Addenbrooke's Cognitive ExaminationRevised (ACE-R), would be a more useful tool to be implemented in clinical practice having a high sensitivity (0.82) and high specificity (0.89) [18]. The administration of the scale is proven to be easy and taking approximately 15 mins which makes it practical in a clinical environment [19]. Weighted comparison of the two scales indicated a net benefit for ACE-R vs. MMSE (0.18), confirming the diagnostic superiority of ACE-R to MMSE particularly its sensitivity to detection of dementia [18], further validating its use in physiotherapy based clinical practice.

Pain is a symptom very commonly treated by a physiotherapist. Along with affecting cognition, function, motivation, it has a significant impact on patient's response to active rehabilitative intervention. People experiencing dementia connected with verbal impedance will most likely be unable to report torment as effortlessly and are at a risk of receiving insufficient medication and treatment of pain [15]. It is accordingly crucial that pain is evaluated earlier and amid treatment to permit recovery Horgas 2003. The most common outcome measure used by physiotherapists to assess pain is VAS or NRS; however, this may only be used in cases of early stages of dementia and would be impractical in patients with verbal impedance. Hence, the integration of Pain Assessment in Advanced Dementia (PAINAD) scale in clinical practice would be valuable. This behaviour-observation tool is developed to detect pain in dementia patients having difficulty in communicating. The scale takes into consideration the breathing patterns, negative vocalization, body language, facial expressions and consol ability [20]. This is of extreme significance as the prevalence of pain or potentially painful conditions is high in older adults with dementia in long term ranging from $43 \%$ to $71 \%$ [21]. The scale also has moderate reliability (Cronbach's a coefficient ranging from 0.30 to 0.83), along with high interrater reliability ( $r=0.93-0.97)$, further validating its use in clinical practice by physiotherapists [20]. Pain is a standout amongst the most widely managed symptoms treated by physiotherapists and hence accurate assessment of pain may have the capacity to offer appropriate interventions for the agony e.g. - TENS, gentle exercises and massage.

Along with mental and cognitive debility, dementia is also associated with physical deconditioning, frailty and impaired balance. Balance and cognition are the major components of functional capacity in patients, and hence need to be targeted by physiotherapists during treatment. A recent study conducted on motor interventions by physiotherapists in collaboration with occupational therapists have been suggested to have improved balance in institutionalized dementia patients, with little effect on the cognitive domains [22]. Improvement in balance will in turn prevent falls; improve function and ADL's. The protocol involved kinesio-therapeutic exercises that promoted strength, balance and cognition such as concentrated attention, recognition, immediate memory and working memory [23]. This indicates the positive effects of exercises on patients and ascertains its use as a part of physiotherapy management in dealing with patients with dementia. Dementia is a condition primarily governed by decline in memory and cognition. However, some aspects of cognitive function are preserved until late in the disease and can therefore be the targets of specific interventions Patterson 1994. Available evidence suggests Reminiscence Therapy which utilizes the patient's memory to retain/ improve optimum cognition Cotelli 2012. Cognitive Stimulation therapy has also been suggested to show worthwhile benefits for dementia Spector 2003. Physiotherapists can therefore, in collaboration with trained individuals or psychiatrists incorporate these techniques to their treatment ensuring a holistic approach and optimal patient centred care.

Family carers are a noteworthy contributor of assistance and help to the persons they offer care to alongside being real benefactors to the welfare framework, balancing the national human services expenditure Stoltz 2004. Therefore, along with having responsibilities towards the patients themselves, physiotherapists must also consider the role of carers. Carers of individuals with dementia often display declined health condition when compared their agematched peers [24] and physiotherapists can assist in reducing the burden of care by instructing carers to empower autonomy in individuals with dementia. Recent literature additionally proposes a connection between caregiver's needs and the burdens they carry Rosa 2009. In spite of the regard for the patients families' play in nurturing patients with a diagnosis of dementia, carers still express low levels of disease cognizance and abnormal amounts of mental turmoil [25]. Taft in 1978, presented a psychosocial model of dementia care, endorsing Social and mental methodologies empowering guardians to make a therapeutic milieu that offers support, inclusion, and approval to persons with dementia. Both social and psychological approaches are ways of protecting personhood- the focal centre of dementia [26]. Physiotherapists can integrate this model in clinical practice by using strategies such as empathic car- 
ing, supportive touch, being supportive, offering choices, reframing instructions implied by the model, in order to build a successful therapeutic relationship Taft 1978.

\section{Summary}

Physiotherapy is a significant factor in rehabilitation of patients with dementia and must adapt a holistic approach during assessment and treatment [27], taking into consideration all the factors affecting patient centred-care.

\section{Reflection}

Reflection is considered to be an important aspect in clinical reasoning and decision making in physiotherapy practice. The following piece of self-reflection will shed light on my learning process throughout the Personalised study Module and identify areas of self-improvement. Having had a keen interest in dementia, and the eagerness to learn how I would be able to contribute to the rehabilitation of demented patients as a physiotherapist, this module has helped me learn in abundance not only about the condition, but also the factors that would influence physiotherapy treatment in dementia. Given the opportunity to treat dementia, there are numerous things I would do differently. Being more aware of the scope of physiotherapy in dementia, I would be mindful of my role in rehabilitation. Addressing the physical deficits as well as the emotional turmoil the patient is experiencing would be one of the key points I have learnt from this module. As a physiotherapist, having little or no experience working with dementia patients, I am more accustomed to target the physical problems and curing it. However, this would drastically change in terms of interaction, assessment and treatment delivery with dealing with patients suffering dementia. Having better knowledge of the condition and symptoms, assessment will be one aspect I will pay heed to in particular [28]. While interacting with patients, I will inculcate the use the unique communication skills needed to better interact with patients such as use of short simple sentences, use of visual cues, repetition of information when needed etc. Body language also has a positive impact on the therapeutic relationship and I will be sure to use better eye contact and posture. My approach would primarily include collaboration with friends and family to gain collateral information about patient's previous life, interest and personality of the patient before being diagnosed, to allow for a tailor-made assessment and treatment protocol for the individual. Being more aware of the political impact of the disorder, practising in India, I would be sure to educate myself of the patient's cultural beliefs and socio-economic status. This would essentially be vital in government hospitals, where majority of the patients treated belong to an extremely low socio-economic background. There is also lack of awareness of the disease, hence my responsibilities would include educating the patient/ family, counselling the caregivers of the prognosis and instructions for home care. This would further assist the patient and the family make decisions throughout the disease process [29].

Being more acquainted with the current research in this field, my approach to assessment and treatment would be more evidence based. Having previously used MMSE for cognitive evaluation,
I would now integrate the ACE-R scale for assessment due to its high diagnostic sensitivity as well as its simple and speedy administration method. This would allow me to diagnose patients during the early stages of the disease and further improve their prognosis. For patients in the terminal stages of the disease, I would utilise the PAINAD scale to identify the levels of pain when the patient is unable to communicate and would in turn provide appropriate treatment of the same [30]. Treatment protocol would involve collaboration with psychologists or adaptation of a MultiDisciplinary team to practice approaches such as Reminiscence Therapy and Cognitive Stimulation therapy whenever appropriate. Rehabilitation would also involve prescription of easy exercises to maintain mobility and improve mood and reduce anxiety along with memory aids to help patients remember the exercise program to ensure patient adherence. Similarly, the above would also apply for any patient presenting with cognitive impairment. For instance, vascular dementia is a common consequence of stroke commonly treated by physiotherapists.

\section{Conclusion}

In conclusion, my approach towards treating patients would be more holistic taking into all the factors affecting the patient and would involve integration of the newly learnt assessment and treatment techniques. My rehabilitation approach will focus on achieving a balance between ensuring optimal function, promoting independence and reality of dementia being a progressive disorder and will in time hinder patients functioning.

\section{Appendix I \\ Dementia V/S Normal ageing}

Dementia is principally a syndrome of later life, with its prevalence and incidence rising sharply with advancing age. Age has been identified as the most predominant aspect for Alzheimer's disease which is the most common form of dementia in most diseases Aronson 1991. Age is likewise connected with the risk factors for vascular dementia. At the point when turmoil is so strikingly age dependant, it is critical to analyse the relationship to typical maturing [31]. Unlike dementia, the idea of typical maturing is inadequately understood. Many of the co-morbidities of ageing that result in disabilities such as cancer, prostate disease and hormonal inadequacies have ended up treatable which challenges the belief that they are inescapable components of the physiological procedure and recommends that they might be viewed as pathologic conditions.

In the first study conducted by [32], examining the presence of changes in white matter three major types of late life dementia which included Alzheimer's, dementia with Lewy bodies and vascular dementia, per ventricular hyper intensities and White matter hyper intensities (WMH) were found frequently in patients with dementia and age coordinated controls. These progressions were, however, altogether broader in the dementia cohorts. The inference of the above was later clarified in a review and Metaanalysis which related the movement of WMH with deterioration in memory execution, conceptualisation and visiopractical skills 
along with a faster decline of executive functions or processing speed. Thus, White matter hyper intensities foresee an expanded danger of stroke, dementia, and demise, serving as an indicator of high susceptibility. Their revealation should thereby prompt detailed screening for risk factors of dementia $[33,34]$.

\section{Appendix II}

\section{Types of dementia}

Alzheimer's disease: Alzheimer's is the most common type of dementia accounting for about $50 \%-70 \%$ of the reported cases [35], although some of these are in combination with vascular dementia and/or dementia with Lewy Bodies. Alzheimer's disease is characterized by a progressive decline in cognitive function, which typically begins with deterioration in memory. Survival with Alzheimer's disease varies from 2 to 20 years, but a more realistic estimate of survival is 3 to 4 years. Helmer 2001 Symptoms may be present for several years before diagnosis. There is evidence that brain abnormalities may be present for up to 30 years before symptoms become apparent, therefore, the true course of the disease is much longer, thereby reinforcing the importance of early diagnosis of the condition [36]. NICE Guidelines for diagnosis of dementia includes a comprehensive analysis and patient assessment which includes:

\section{A. History taking}

B. Cognitive and mental state examination

C. Physical examination and other appropriate investigations

D. Details of the drugs patient may be taking that may have had an adverse effect on the cognitive Functioning of the individual

E. Practicing confidentiality- The guideline advises prac- titioners to ask the patients who they would like to share the news of the diagnosis with

F. Clinical cognitive assessment must be administered which may include the mini mental scale examination (MMSE), 6 item cognitive impairment test

\section{Vascular dementia}

Vascular dementia may result from single or multiple causes. It comprises of a group of conditions, including multi infarct dementia, sub cortical dementia, Binswanger's sub cortical arteriosclerotic encephalopathy Curran 2004.

The main causes include:

A. Hemodynamic (blood flow to the brain. E.g. - stroke).

B. Thromboembolism (blood clots originating mainly from the carotid artery or heart that block blood vessel in brain).

C. Haemorrhage (bleeding in or around the brain subarachnoid, intracerebral or subdural).

Clinical features: The onset is ordinarily following 65 years old and may follow cerebral infarct. It may, therefore, present more acutely than Alzheimer's disease. Arteriosclerotic changes may be present in the peripheral and retinal blood vessels, and the patient may have hypertension, along with emotional and personality changes. Its main clinical features include [37].
A. A step wise progression
B. Patchy impairment of cognitive functioning,
C. Depression and anxiety
D. Seizures
E. Transient Ischemic Attacks (TIA)

Table 3: Clinical features of Alzheimer's disease Curran 2004.

\begin{tabular}{|c|c|}
\hline Stage & Symptoms \\
\hline \multirow{7}{*}{ Early Stage } & Memory impairment \\
\hline & Difficulty performing everyday tasks \\
\hline & Impaired concentration \\
\hline & Spatial disorientation \\
\hline & Disturbances of mood - depression, euphoria or liability of mood \\
\hline & Fatigue, anxiety and lack of spontaneity \\
\hline & Several patients maintain good social competence despite severe cognitive impairment. \\
\hline \multirow{7}{*}{ Intermediate Stage } & Apraxia and agnosia \\
\hline & Deterioration in reading and writing ability \\
\hline & Disorientation in time and place \\
\hline & Speech problems (nominal dysphagia) \\
\hline & Emotional liability and catastrophic reactions \\
\hline & Extra pyramidal disorder (increased muscle tone and altered gait) \\
\hline & Delusions and/or hallucinations. \\
\hline
\end{tabular}




\begin{tabular}{|l|c|}
\hline \multirow{4}{*}{ Late Stage } & Double incontinence \\
\cline { 2 - 3 } & Lack of communication \\
\cline { 2 - 3 } & Emaciation \\
\cline { 2 - 3 } & Limb contractures \\
\cline { 2 - 3 } & Grand mal seizures \\
\hline
\end{tabular}

F. Episodes of confusion and personality change (Table 3).

The life span averages 4 to 7 years from the time of diagnosis, though it may be much longer. Death may result from ischemic heart disease, cerebra infarction or renal complications.

\section{The hachinski score}

Table 4: Hachincki score.

\begin{tabular}{|c|c|}
\hline Features & Score \\
\hline Abrupt onset & 2 \\
\hline Stepwise deterioration & 1 \\
\hline Fluctuating course & 2 \\
\hline Nocturnal confusion & 1 \\
\hline Relative preservation of personality & 1 \\
\hline Depression & 1 \\
\hline Somatic complaints & 1 \\
\hline Emotional incontinence & 1 \\
\hline History of hypertension & 1 \\
\hline History of strokes & 2 \\
\hline Atherosclerosis & 2 \\
\hline
\end{tabular}

\begin{tabular}{|c|c|}
\hline Focal neurological symptoms & 2 \\
\hline Focal neurological signs & 2 \\
\hline
\end{tabular}

Hachinski in 1975 built up a scoring framework which has been generally utilized as a guide to help clinicians differentiate between vascular dementia and Alzheimer's disease [38-45]. The components are weighted and the scores of all elements present are added to give an aggregate score. A score above 6 demonstrates vascular dementia (Table 4).

\section{Dementia with lewy bodies}

Dementia with Lewy bodies has only been recognised as a distinct entity since 1996 when consensus guidelines for the diagnosis first appeared [46-50]. It is estimated to account for about $5 \%$ of dementia cases with approximately $15 \%$ occurring in combination with Alzheimer's disease World Alzheimer's report 2009. It tends to occur in range of age 50 to 85 years and is slightly more common in males. The mean duration of the disease is four and a half years, though it ranges from 1 to 20 years [51-56]. Lewy bodies are neuronal inclusion bodies found in the cerebral cortex and substantia nigra of the brain (Table 5,6). These bodies can be present in the brain without impinging upon functioning to a degree to warrant diagnosis, however, where a large number are present, dementia results [57-63].

Table 5: A diagnosis of vascular dementia requires the following ICD-10 criteria to be met.

\begin{tabular}{|c|c|}
\hline No & Diagnostic Criteria \\
\hline 1 & The general criteria for dementia \\
\hline 2 & Deficits in higher cognitive function are unevenly distributed, with some functions affected and others relatively spared \\
\hline & Clinical evidence of focal brain damage, manifest in at least one of the following: \\
& Unilateral spastic weakness of the limbs \\
& Unilaterally increased tendon reflexes \\
& An extended palmer response \\
\hline 4 & Pseudo bulbar palsy \\
\hline
\end{tabular}

Table 6: Keywords.

\begin{tabular}{|c|c|}
\hline Keyword & Justification \\
\hline Dementia & This condition is the main focus of research. \\
\hline Alzheimer's Disease & The most commonly presenting subtype of dementia. \\
\hline AD & Commonly used abbreviation for the above \\
\hline Physiotherapy & $\begin{array}{r}\text { The treatment intervention in focus to investigate the role of physiotherapy in the management of dementia. Hence, includ- } \\
\text { ing the term will aide in refining the search and obtaining results specific to physiotherapy. }\end{array}$ \\
\hline
\end{tabular}




\begin{tabular}{|c|c|}
\hline Occupational Therapy & $\begin{array}{c}\text { Adjunct treatment approach which may be integrated with respect to the assessment and rehabilitation to those methods } \\
\text { already being used in physiotherapy. }\end{array}$ \\
\hline OT & Commonly used abbreviation for the above \\
\hline
\end{tabular}

\section{Clinical features}

A. Fluctuation in cognitive performance and level of consciousness, with pronounced variations is attention and alertness.

B. Visual hallucinations

C. Depression

\section{Appendix IV}

\section{Search strategy}

Table 7: Boolean logic for searching databases.

\begin{tabular}{|c|c|c|c|}
\hline Search Query & $\begin{array}{l}\text { Boolean } \\
\text { Logic }\end{array}$ & Field & Search Term(s) Good \\
\hline 1 & & Any field & $\begin{array}{c}\text { Dementia OR “Vascular Dementia" OR "Alzheimer's Disease" OR "AD" OR “mental incapacity" OR "cog- } \\
\text { nitive impairment" OR "fragility" }\end{array}$ \\
\hline 2 & AND & Any field & "Physiotherapy" OR "Physical therapy" OR "PT" "Occupational therapy" OR "OT" \\
\hline 3 & AND & Any field & effect* OR rehab* OR improvement OR potential \\
\hline 4 & NOT & Any field & Animals or children. \\
\hline
\end{tabular}

Relevant databases were selected, and a systematic and comprehensive search was conducted for specific articles related to the research topic. Appropriate results obtained from the search were then filtered and minimised to the most suitable articles in

relation to dementia [63-66]. The search was carried out with the help of key words and Boolean logic (Table 7) in order to achieve the most appropriate results.

Table 8: Inclusion criteria.

\begin{tabular}{|c|c|}
\hline Inclusion Criteria & Rationale \\
\hline \multirow[b]{2}{*}{ Studies including patients with dementia } & Dementia is the condition being studied and focussed on in the research question. \\
\hline & $\begin{array}{c}\text { Studies including patients diagnosed with dementia were included along with patients } \\
\text { presenting with symptoms of dementia as a result of an underlying condition. E.g. - vascular } \\
\text { dementia post stroke. }\end{array}$ \\
\hline $\begin{array}{l}\text { Studies investigating the effectiveness of Physiotherapy } \\
\text { assessment / treatment approaches in dementia }\end{array}$ & $\begin{array}{l}\text { Physiotherapy is the key mode of rehabilitation specified within the research report. Studies } \\
\text { using Physiotherapy as a co intervention were also used. }\end{array}$ \\
\hline $\begin{array}{l}\text { Studies investigating the effectiveness of Occupa- } \\
\text { tional therapy assessment / treatment approaches in } \\
\text { dementia. }\end{array}$ & $\begin{array}{l}\text { These approaches may be implemented by physiotherapists in order to effectively rehabili- } \\
\text { tate patients with dementia. }\end{array}$ \\
\hline $\begin{array}{l}\text { Studies investigating the additional aspects associated } \\
\text { with dementia. }\end{array}$ & $\begin{array}{l}\text { Dementia being a multi-factorial group of symptoms, it is important to understand the nu- } \\
\text { merous aspects that must be considered in holistic patient centred care }\end{array}$ \\
\hline
\end{tabular}

Table 9: Exclusion criteria.

\begin{tabular}{|c|c|}
\hline $\begin{array}{c}\text { Exclusion Criteria } \\
\begin{array}{c}\text { Studies not investigating the relevance of physiother- } \\
\text { apy in dementia }\end{array}\end{array}$ & $\begin{array}{c}\text { The efficacy of physiotherapy is the specific management method under investigation within } \\
\text { the research question. }\end{array}$ \\
\hline $\begin{array}{c}\text { Studies including young participants presenting with } \\
\text { dementia. }\end{array}$ & $\begin{array}{c}\text { Studies including subjects with early onset dementia as these patients and their careers have } \\
\text { different needs to the older population commonly affected [10] }\end{array}$ \\
\hline Grey literature. & $\begin{array}{c}\text { Articles and papers which are difficult to find in the academic databases and indexes make it } \\
\text { unfeasible them. }\end{array}$ \\
\hline Literature in any language other than English. & Unfeasible to translate the articles in English to be reviewed. \\
\hline
\end{tabular}

Inclusion and exclusion criteria: The results obtained from the pertinent databases were then filtered using the inclusion and exclusion criteria to find the most appropriate and useful research articles (Table 8,9).

\section{References}

1. Draper B (2013) Understanding alzheimer's disease and her dementias. Jessica Kingsley Publishers, UK.

2. Reitz C, Brayne C, Mayeux R (2011) Epidemiology of alzheimer disease. Nat Rev Neurol 7(3): 137-152. 
3. Webber PA, Fox P, Burnette D (1994) Living alone with Alzheimer's disease: effects on health and social service utilization patterns Gerontologist 34(1): 8-14.

4. Appelbaum PS and Grisso T (1988) Assessing patient's capacities to consent to treatment. N Engl J Med 319(25): 1635-1638.

5. Charles C, Gafni A, Whelan T (1997) Shared decision-making in the medical encounter: what does it mean? (Or it takes at least two to tango). Soc Sci Med 44(5): 681-692.

6. Butcher HK, Holkup PA, Park M, Maas M (2001) Thematic analysis of the experience of making a decision to place a family member with alzheimer's disease in a special care unit. Res Nursing Health 24(6): 470-480.

7. Dias A, Patel V (2009) Closing the treatment gap for dementia in India. Indian J Psychiatry 51 (Suppl 1): S93-S97.

8. Hughes JC, David J, Alice J, Elizabeth LS (2007) Palliative care in dementia: issues and evidence. Advances in Psychiatric Treatment 13(4): 251-260.

9. Heyn P, Abreu BC, Ottenbacher KJ (2004) The effects of exercise training on elderly persons with cognitive impairment and dementia: a metaanalysis. Arch Phys Med Rehabil 85(10): 1694-1704.

10. Pomeroy VM (1993) The effect of physiotherapy input on mobility skills of elderly people with severe dementing illness. Clinical rehabilitation $7(2): 163-170$.

11. Bourgeois MS (2002) Where is my wife and when am I going home? The challenge of communicating with persons with dementia. Alzheimer's Care Today 3(2): 132-144.

12. Allan K (2001) Communication and consultation: exploring ways for staff to involve people with dementia in developing services. Policy Press.

13. Thornquist E (1991) Body communication is a continuous process: the first encounter between patient and physiotherapist. Scand Journal Prim Health Care 9(3): 191-196.

14. Watzlawick P, Beavin J (1967) Some formal aspects of communication The American behavioural scientist (pre-1986) 10(8): 4

15. Marshall M (2005) Perspectives on rehabilitation and dementia. Jessica Kingsley Publishers, UK.

16. Porter S (2013) Tidy's physiotherapy. Elsevier Health Sciences, USA.

17. Galea M, Woodward M (2005) Mini mental state examination (MMSE). Aust J Physiother 51(3): 198

18. Larner AJ, Hancock P (2014) ACE-R or MMSE? A weighted comparison. Int J Geriatr Psychiatry 29(7): 767-768.

19. Mioshi E, Dawson K, Mitchell J, Arnold R, Hodges JR (2006) The Addenbrooke's Cognitive Examination Revised (ACE-R): a brief cognitive test battery for dementia screening. Int J Geriatr Psychiatry 21(11): 1078-1085

20. Horgas A, Miller L (2008) Pain assessment in people with dementia. Am J Nurs 108(7): 62-70.

21. Orange JB, Colton HA (1996) Enhancing communication in dementia of the alzheimer's type. J Speech Hear Res 39(4): 881-895.

22. Christofoletti G, Oliani MM, Gobbi S, Stella F, Bucken Gobbi LT, et al (2008) A controlled clinical trial on the effects of motor intervention on balance and cognition in institutionalized elderly patients with dementia. Clin Rehabil 22(7): 618-626.

23. Hernandez SS, Coelho FG, Gobbi S, Stella F (2010) Effects of physica activity on cognitive functions, balance and risk of falls in elderly patients with Alzheimer's dementia. Rev Bras Fisioter 14(1): 68-74.

24. Pinquart M, Sörensen S (2003) Differences between caregivers and noncaregivers in psychological health and physical health: a meta analysis. Psychol Aging 18(2): 250-267.
25. Rosa E, Lussignoli G, Sabbatini F, Chiappa A, Di Cesare S, et al. (2010) Needs of caregivers of the patients with dementia. Arch Gerontol Geriatr 51(1): 54-58.

26. Harrison C (1993) Personhood, dementia and the integrity of a life. Canadian journal on Aging/La revue canadienne du vieillissement 12(4): 428-440

27. Gao S, Hendrie HC, Hall KS, Hui S (1998) The relationships between age, sex, and the incidence of dementia and Alzheimer disease: a metaanalysis. Arch Gen Psychiatry 55(9): 809-815.

28. Barber R, Scheltens P, Gholkar A, Ballard C, McKeith I, et al. (1999) White matter lesions on magnetic resonance imaging in dementia with lewy bodies, alzheimer's disease, vascular dementia, and normal aging. J Neurol Neurosurg Psychiatry 67(1): 66-72.

29. Debette S, Markus HS (2010) The clinical importance of white matter hyper intensities on brain magnetic resonance imaging: systematic review and meta-analysis. BMJ 341: c3666.

30. Fratiglioni L, De Ronchi D, Agüero TH (1999) Worldwide prevalence and incidence of dementia. Drugs Aging 15(5): 365-375.

31. Richards SS, Hendrie HC (1999) Diagnosis, management and treatment of alzheimer disease: A guide for the internist. Arch Intern Med 159(8): 789-798.

32. Gelder M, Harrison P, Cowen P (2006) Shorter oxford textbook of psychiatry. Oxford University Press, UK

33. Pantoni L, Inzitari D (1993) Hachinski's ischemic score and the diagnosis of vascular dementia: A review. Italian J Neurol Sci 14(7): 539-546.

34. Mckeith IG, Galasko D, Kosaka K, Perry EK, Dickson DW, et al. (1996) Consensus guidelines for the clinical and pathologic diagnosis of dementia with Lewy bodies (DLB): report of the consortium on DLB international workshop. Neurology 47(5): 1113-1124.

35. Jacoby R, Oppenheimer C (2002) Psychiatry in the Elderly. Oxford University Press, UK.

36. Fratiglioni L, Paillard BS, Winblad B (2004) An active and socially integrated lifestyle in late life might protect against dementia. Lancet Neurol 3(6): 343-353

37. Acosta D, Wortmann M (2009) Alzheimer's disease-international world alzheimer report. pp. 1-92.

38. Agronin ME (2007) Alzheimer disease and other dementias: a practical guide. Lippincott Williams \& Wilkins, USA.

39. Bailey G, Sanderson H (2013) Personalisation and dementia: a guide for person-centred practice. Jessica Kingsley Publishers, UK.

40. Barker DJP, Rose G (1976) Epidemiology in medical practice. In: $\left(5^{\text {th }}\right.$ edn), Churchill Livingston Inc, New York, USA.

41. Beattie AM, Daker WG, Gilliard J, Means R (2002) Younger people in dementia care: a review of service needs, service provision and models of good practice. Aging Ment Health 6(3): 205-212.

42. Brown M (2012) The physiology of age-related and lifestyle-related decline. In: Andrew AG, Rita AW, Avers D (Eds.), (3 ${ }^{\text {rd }}$ edn), Mosby, Saint Louis, USA, pp. 27-37.

43. Curran S, Wattis J (2003) Practical management of dementia: a multiprofessional approach. Radcliffe Publishing, UK.

44. Duyckaerts C, Litvan I (2008) Alzheimer's disease: epidemiology. Dementias 195.

45. Ferri CP, Jackson J, Prince M (2010) The global challenge of dementia: what can be done. Dementia ( $4^{\text {th }}$ edn), Hodder arnold, London, pp. $341-$ 348.

46. Ferri CP, Prince M, Brayne C, Brodaty H, Fratiglioni L, et al. (2005) Global prevalence of dementia: a Delphi consensus study. Lancet 366(9503): 2112-2117. 
47. Flicker L (1999) Dementia reconsidered: the person comes first. BM] 318(7187): 880A.

48. Flores P (2013) The tau protein: From physiological to pathological process in alzheimer's disease. Alzheimer's \& Dementia. The Journal of the Alzheimer's association 9(4): P366.

49. Gyllensten AL, Hansson L, Ekdahl C (2017) Patient experiences of basic body awareness therapy and the relationship with the physiotherapist. J Bodyw Move Ther 17(2): 169-176.

50. Harding AJ, Broe GA, Halliday GM (2002) Visual hallucinations in lewy body disease relate to Lewy bodies in the temporal lobe. Brain 125(Pt 2): 391-403.

51. Hardy J, Selkoe DJ (2002) The amyloid hypothesis of alzheimer's disease: Progress and problems on the road to therapeutics. Science 297(5580): 353-356.

52. Hebert R, Dubois MF, Wolfson C, Chambers L, Cohen C (2001) Factors associated with long-term institutionalization of older people with dementia: data from the canadian study of health and aging. J Gerontol A Biol Sci Med Sci 56(11): M693-M699.

53. Koutsavlis AT, Wolfson C (2000) Elements of mobility as predictors of survival in elderly patients with dementia: findings from the canadian study of health and aging. Chronic Dis Can 21(3): 93-103.

54. Martin A, Fedio P (1983) Word production and comprehension in Alzheimer's disease: The breakdown of semantic knowledge. Brain and Lang 19(1): 124-141.

55. May H, Edwards P, Brooker D (2009) Enriched care planning for people with Dementia: A good practice guide to delivering person-centred care. Jessica Kingsley Publishers, UK.

56. Mckhann GM, Knopman DS, Chertkow H, Hyman BT, Jack CR, et al. (2011) The diagnosis of dementia due to Alzheimer's disease: recommendations from the national institute on aging-alzheimer's association workgroups on diagnostic guidelines for alzheimer's disease. Alzheimers Dement 7(3): 263-269.

57. Moberg KU (2003) The oxytocin factor: Tapping the hormone of calm, love, and healing. Da Capo Press, USA.

58. Murphy J, Gray CM, Cox S (2007) Communication and dementia. How talking mats can help people with dementia to express them, Joseph Rowntree Foundation, New York, USA.

59. Nelson ME, Rejeski WJ, Blair SN, Duncan PW, Judge JO, et al. (2007) Physical activity and public health in older adults: recommendation from the american college of sports med and the american heart association. Med Sci Sports Exerc 39(8): 1435-1445.

60. Prince M, Acosta D (2006) Ageing and dementia in developing countriesthe work of the 10/66 Dementia Research Group.

61. Prince M, Bryce R, Albanese E, Wimo A, Ribeiro W, et al. (2013) The global prevalence of dementia: A systematic review and metaanalysis. Alzheimers Dement 9(1): 63-75.

62. Selkoe DJ (2001) Alzheimer's disease: Genes, proteins, and therapy. Physiol Rev 81(2): 741-766.

63. Shimohama S (2000) Apoptosis in Alzheimer's disease-an update. Apoptosis 5(1): 9-16.

64. Wimo A, Jönsson L, Bond J, Prince M, Winblad B, et al. (2013) The worldwide economic impact of dementia 2010. Alzheimer's Dement 9(1): 1-11e3.

65. Horgas AL, Mclennon SM, Floetke AL (2004) Pain management in persons with dementia. Nurs Clin North Am 39(3): 593-606.

66. Huppert FA, Brayne C (1994) Dementia and normal aging. Cambridge University Press, UK.

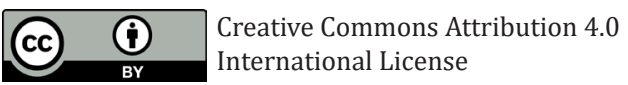

For possible submissions Click Here
Submit Article

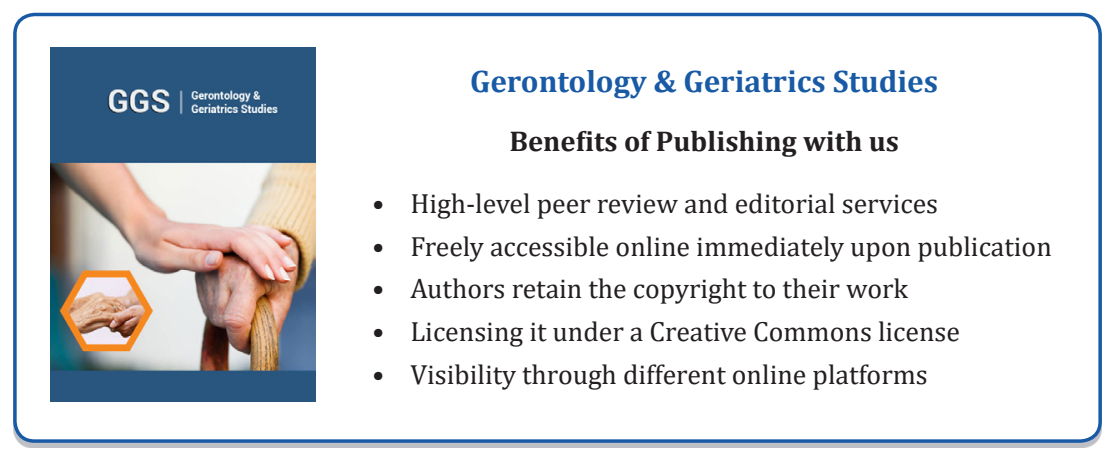

